\title{
Effect and Safety of Anti-PD-1/PD-L1 Monotherapy for Metastatic Breast Cancer: A meta-analysis
}

\section{Yihang Qi ( $\nabla$ qiyihang@qq.com )}

Chinese Academy of Medical Sciences and Peking Union Medical College https://orcid.org/0000-0001-7589-0333

Xiangyi Kong

Chinese Academy of Medical Sciences \& Peking Union Medical College Institute of Medical Information

Xiangyu Wang

Chinese Academy of Medical Sciences \& Peking Union Medical College Institute of Medical Information

Jie Zhai

Chinese Academy of Medical Sciences and Peking Union Medical College

\section{Yi Fang}

Chinese Academy of Medical Sciences and Peking Union Medical College

Jing Wang

Chinese Academy of Medical Sciences and Peking Union Medical College

\section{Research article}

Keywords: Anti-PD-1/PD-L1 antibodies, breast cancer, effect, safety, immunotherapy

Posted Date: August 5th, 2019

DOI: https://doi.org/10.21203/rs.2.12425/v1

License: (c) (1) This work is licensed under a Creative Commons Attribution 4.0 International License. Read Full License 


\section{Abstract}

Background. Given that no approved targeted agents for metastatic triple-negative breast cancer (mTNBC) and no opportunity of surgery for metastatic breast cancer (MBC), new treatment options are urgently to be discovered. The anti-PD-1/PD-L1 immunotherapy may be effective, and what we should be aware of is the response rate and adverse events. Methods. The PUBMED, EMBASE, Cochrane and www.clinicaltrials.gov databases were searched to find potential studies using the following strategies: anti-PD-1/PD-L1; metastatic; breast cancer. R@ package Meta was used to pool incidence. Results. Six studies including 586 advanced breast cancer patients treated with anti-PD-1/PD-L1 agents were included in this meta-analysis. The anti-PD-1/PD-L1 agents include pembrolizumab, atezolizumab and avelumab. Among these patients, CR was $1.26 \%$, PR was $7.65 \%$, ORR was $9.85 \%$ and DCR was $18.33 \%$. We also found that the response rate was closely associated with the expression of PD-L1 biomarker (PD-L1+ vs PD-L1-): the CR was $2.71 \%$ vs $0.00 \%$; the PR was $9.93 \%$ vs $2.69 \%$; the ORR was $10.62 \%$ vs $3.07 \%$; the DCR was $17.95 \%$ vs $4.71 \%$. 1-year overall survival rate and 6-months progression-free survival rate were $43.34 \%$ and $17.24 \%$. Respectively, the overall incidence of AEs was $64.18 \%$ in any grade and $12.94 \%$ in severe grade. The incidence of irAEs was $14.75 \%$. Besides, the incidence of discontinue and death due to treatment-related AEs was about $3.06 \%$ and $0.31 \%$ respectively. When the detailed AEs were analyzed, most treatment-related AEs of any grade were arthraigia, asthenia, decreased appetite; most common treatment-related AEs of severe grade were anemia, autoimmune hepatitis, diarrhea; the most common irAEs were hypothyroidism, followed by hyperthyroidism, pneumonitis and infusion-related reaction. Conclusions. Anti-PD-1/PD-L1 monotherapy showed a manageable safety profile and had a durable anti-tumor clinical activity in a subset of patients with mTNBC or MBC. PD-L1 expression may be correlated to a higher probability of clinical response.

\section{Background}

The latest data showed that up to $30 \%$ of women with non-metastatic, early-stage breast cancer at first diagnosis will finally develop distant metastatic disease, and up to $6 \%$ of women diagnosed with breast cancer in the United States have metastatic disease at the time of first visit. The impact of new chemotherapeutic and hormone agents on survival in a population-based cohort of women with metastatic breast cancer[1-4]. Although advances in the treatment of metastatic breast cancer(MBC) and an encouraging median overall survival time approaches to 24 months (vary from months to years), known as an incurable and fatal disease subtype, advanced breast cancer still remains a vitally significant threat to the wellness of women all over the world[5, 6], making it a pressing priority to discover novel and effective approaches to improve overall survival and prognosis of patients who suffered from this dangerous disease.

With the goal of being an individualized and tailored approach, the therapeutic strategy of MBC depends on both clinical factors and tumor biology, including systemic medical treatment consisting of chemotherapy, endocrine therapy, and/or biologic therapies, and supportive care measures[7, 8]. What's worse is that as for metastatic triple-negative breast cancer (mTNBC) patients (whose median OS is 8 to 13 months, accounting for 15-20\% of breast cancer patients) [9, $10]$, there is no approved targeted treatment available, other than the administration of cytotoxic chemotherapy, which turned out to be a poor clinical outcome[11-13]. Thus, novel and effective therapies are urgently needed for MBC especially mTNBC patients whose disease has continuous progressed even following standard therapies.

Immunotherapy comprises a promising and tolerable new area in breast cancer therapy. Programmed death-1 (PD-1) is an inhibitory trans-membrane receptor expressed on the surface of immune effect cells including B cells, T cells, DCs, NK cells, and many TILs, and two ligands of PD-1 called PD-L1 and PD-L2 have been identified[13]. In 2011, by targeting either the PD-1 receptor or its ligand PD-L1, these immune checkpoint inhibitors were first approved by the Food and Drug Administration (FDA) for applying to advanced metastatic melanoma. Moreover, with the emerging of a large number of research about PD-L1/PD-1 inhibition and breast cancer, preliminary data from several qualified clinical trials presented promising outcomes for patients with advanced stage/metastatic breast cancer. In this meta-analysis study, we conducted the present available data of several qualified studies to explore the efficacy and safety of anti-PD-1/PD-L1 monotherapy for MBC.

\section{Methods}

\section{Literature Searches}

We searched PUBMED, EMBASE, Cochrane and www.clinicaltrials.gov databases to determine eligible studies from database inception to March 1, 2019. With no restriction on language, the strategy we used was as follows: (anti-PD-1 OR anti-PD-L1 OR nivolumab OR pembrolizumab OR atezolizumab OR avelumab OR BMS-936559 OR durvalumab) AND (metastatic OR advanced) AND breast cancer. All words available for Medical Subject Headings (MeSH) were searched by MeSH. The references of included studies as well as relevant reviews were screened either, in order to acquire some other potential studies. Conference abstracts before March 1, 2019 were also searched.

\section{Selection Criteria}

Eligible studies included in our meta-analysis were required to meet the following criteria: (1) Prospective clinical trials; (2)Patients were diagnosed with advanced/metastatic breast cancer that were treated with anti-PD-1/PD-L1 agents monotherapy; (3)Oncologic therapy prior to anti-PD-1/PD-L1 treatment was acceptable; (4)Study the efficacy or safety of this therapy. (5) Research report-specific data related response rate (WHO Criteria) and adverse events (AEs).

The exclusion criteria were: (1) Non-oncologic patients treated with anti-PD-1/PD-L1 agents; (2) Oncologic patients treated with anti-PD-1/PD-L1 agents combined with other treatments simultaneously; (3)Case reports, basic research, reviews, systematic reviews and meta-analysis, letters, editorials, and expert opinions; (4) Duplicate publications or unpublished studies. 


\section{Data Extraction}

The titles and abstracts of all studies retrieved were independently reviewed by two authors. Then, the full texts of all potentially eligible studies were assessed. A standardized, pre-piloted form was used to extract relevant information from the included studies.

The efficacy outcomes were: complete response(CR); partial response (PR); objective response rate (ORR) and disease control rate (DCR) according to Version 1.1 of the Response Evaluation Criteria in Advanced Solid Tumors version (RECIST version). The primary safety outcomes were detail adverse events and incidence of adverse events(AEs), immune-related AEs (irAEs) and their grade (1-5; recorded according to Version 4 of the Common Terminology Criteria for Adverse Events of the National Cancer Institute, CTC for AE version). Grades $\geq 3$ were evaluated as severe or high grade. The secondary outcome was incidence of death due to treatment related AEs. Any discrepancies or problems arisen were solved by our discussion. Missing data were acquired and ascertained from the principle investigator by e-mails.

\section{Quality Assessment}

The risk of bias for the studies included was assessed by two independent investigators according to the Cochrane Risk of Bias Tool and used a weighted Cohen's kappa coefficient ( $\mathrm{k}$ ) to measure agreement[14].We assessed the following components: sequence generation, blinding, allocation concealment, completeness of outcome data, incomplete outcome data, and other types of bias. Problems and disagreements were resolved by our discussion until we reached an agreement.

\section{Statistical Analysis}

The CR, PR, ORR, DCR and incidence of AEs, irAEs, severe AEs were pooled and estimated for the included studies in this meta-analysis. Heterogeneity between studies was assessed by $Q$ test and $\mathrm{I}^{2}$ statistics. If the $\mathrm{I}^{2}$ value was less than $50 \%$, the meta-analysis was performed using the fixed-effects model. Otherwise, the random-effects model was selected. Potential publication bias was examined by Egger's test. Incidence and subgroup analyses was calculated using $R$ software [R version 3.5.2] with package Meta function. RR was calculated using IBM SPSS Statistics 22.

\section{Results}

\section{Literature Search}

Our search strategy identified 532 potential articles. 454 studies were excluded due to duplicates. The remaining 78 articles were screened for titles and abstracts, and 57 articles were removed based on our inclusion or exclusion criteria. Furthermore, 15 studies were dropped because they did not contain our data of interest. Finally, 6 studies were included in our meta-analysis. The study selection is shown in Figure 1.

\section{Study Characteristics}

The detailed information of the clinical trials involved is presented in Table 1. Overall, 6 studies comprising 586 advanced breast cancer patients treated with anti-PD-1/PD-L1 agents were included in this meta analysis [15-20](Table 1). Among these 6 studies, 5 studies were phase I clinical trials, and the other one was phase II clinical trial, and all of them were single group assignment. There were 4 studies involving pembrolizumab treatment (306 patients), one trial involving atezolizumab treatment (115 patients), and the other one trial involving avelumab treatment (168 patients). Among these 586 patients, 454 patients were TNBC, and 417 patients were PD-L1+ (PD-L1 positive status was defined as PD-L1 expressed in $\geq 1 \%$ tumor cells).

\section{Effect}

\section{Global Response Rate and Survival Rate}

The global response rate consists of CR, PR, ORR and DCR. The global CR was $1.26 \%\left(95 \% \mathrm{Cl}, 0.35-2.54 ; \mathrm{I}^{2}, 19.10\right), \mathrm{PR}$ was $7.65 \%\left(95 \% \mathrm{Cl}, 3.32-13.37 ; \mathrm{I}^{2}\right.$, 76.40), ORR was $9.85 \%\left(95 \% \mathrm{Cl}, 4.40-16.95 ; \mathrm{I}^{2}, 81.60\right)$ and DCR was $18.33 \%\left(95 \% \mathrm{Cl}, 12.18-27.59 ; \mathrm{I}^{2}, 79.20\right)$ (Figure 2$)$. 1-year overall survival rate and 6months progression-free survival rate were $43.34 \%\left(95 \% \mathrm{Cl}, 35.70-51.15 ; \mathrm{I}^{2}, 68.70\right)$ and $17.24 \%\left(95 \% \mathrm{Cl}, 10.70-23.78 ; \mathrm{I}^{2}, 67.80\right)(\mathrm{Figure} 3)$.

\section{Biomarker-Associated Analysis}

The response rate was closely associated with the expression of PD-L1 biomarker (PD-L1+ vs PD-L1-): the CR was $2.71 \%$ (95\% Cl, $1.24-4.72 ; \mathrm{I}^{2}$, 05.00) vs $0.00 \%\left(95 \% \mathrm{Cl}, 0.00-1.13 ; \mathrm{I}^{2}, 00.00\right)$; the PR was $9.93 \%\left(95 \% \mathrm{Cl}, 4.85-16.37 ; \mathrm{l}^{2}, 61.60\right)$ vs $2.69 \%\left(95 \% \mathrm{Cl}, 0.01-8.03 ; \mathrm{l}^{2}, 66.70\right)($ Figure 4$)$; the ORR was $10.62 \%$ $\left(95 \% \mathrm{Cl}, 4.67-16.56 ; \mathrm{I}^{2}, 78.80\right)$ vs $3.07 \%\left(95 \% \mathrm{Cl}, 0.00-6.43 ; \mathrm{I}^{2}, 0.00\right)$, [RR,2.935,(1.189,7.244)]; the DCR was $17.95 \%\left(95 \% \mathrm{Cl}, 12.61-25.55 ; \mathrm{I}^{2}, 51.30\right)$ vs $4.71 \%$ $\left(95 \% \mathrm{Cl}, 1.81-12.25 ; \mathrm{I}^{2}, 00.00\right),[\mathrm{RR}, 3.584,(1.337,9.608)]$ (Figure 5).

\section{Adverse Events}

\section{Global Incidence of AEs}


Respectively, the overall incidence of AEs was $64.18 \%\left(95 \% \mathrm{Cl}, 60.43-68.17 ; \mathrm{I}^{2}, 0.00\right)$ in any grade and $12.94 \%\left(95 \% \mathrm{Cl}, 10.36-15.76 ; \mathrm{I}^{2}, 00.00\right)$ in severe grade. The incidence of irAEs was $14.75 \%\left(95 \% \mathrm{Cl}, 11.72-18.06 ; \mathrm{I}^{2}, 47.0\right)$. Besides, the incidence of discontinue and death due to treatment-related $\mathrm{AEs}$ was about $3.06 \%\left(95 \% \mathrm{Cl}, 1.68-4.44 ; \mathrm{I}^{2}, 45.50\right)$ and $0.31 \%\left(95 \% \mathrm{Cl}, 0.00-0.92 ; \mathrm{I}^{2}, 0.00\right)$ respectively (Figure 6$)$.

\section{Detail Incidence of AEs}

When the specific AEs reported in at least 2 studies were analyzed, treatment-related AEs of any grade that occurred in at least $5 \%$ of patients were fatigue (18\%), nausea (12\%), diarrhea (9\%), hypothyroidism ( $8 \%)$, arthraigia (7\%), asthenia (7\%), decreased appetite (7\%), pruritus (7\%) and rash (6\%) (Figure 7 ); treatment-related AEs of severe grade that occurred in at least $1 \%$ of patients were anemia ( $2 \%)$, autoimmune hepatitis $(2 \%)$, diarrhea $(2 \%)$, fatigue (1\%), GGT increased (2\%), nausea (1\%) and pneumonitis (1\%) (Figure 8); the most common irAEs were hypothyroidism (7\%), hyperthyroidism (3\%) and pneumonitis (3\%) followed by infusion-related reaction (2\%) (Figure 9).

\section{Quality Assessment and Publication Bias}

Risk of bias graphs according to Cochrane Risk of Bias Tool was used to evaluate the methodological qualities of the studies. Blinding of participants and personnel was evaluated as a low risk item because many studies were dose-escalation and single-

arm trials. The over all risk of bias was evaluated as low risk. Therefore, the quality of the studies was satisfactory (Table 2). Finally, the Egger's regression test showed no significant publication bias existed in ORR (Egger's test $P=0.1551)$, DCR (Egger's test $P=0.2853)$ and AEs in any grades $($ Egger's test $P=0.2863$ ) (Figure 10).

\section{Discussion}

In recent years, a myriad of innovations such as anticancer drugs, chemotherapy, surgical techniques and radiation have dramatically improved the treatment of cancer. For early-stage breast cancer, survivorship is $>93 \%$ at 5 years[21]. However, for lack of effective and tolerable treatment towards advanced breast cancer, survivorship is overwhelmingly negative. The median overall survival time of MBC patients is up to 24 months (vary from months to years), while the median overall survival of mTNBC patients is just 8 to 13 months. Under this unfavorable scenario, success in finding anti-PD-1/PD-L1 agents is no doubt a good news for those patients suffered from advanced breast cancer.

This is the first meta-analysis report of the clinical activity and long-term safety associated with anti-PD-1/PD-L1 agents monotherapy in patients with metastatic breast cancer. Six relevant studies of high quality including 586 advanced breast cancer patients (454 TNBC patients and 132 patients with other types breast cancer) treated with anti-PD-1/PD-L1 agents were included in this meta-analysis. We observed that approximately 1 in 10 patients treated with PD-1/PD-L1 inhibitors would receive a partial or complete response, and at least 1 in 6 patients have access to achieve disease control. More than 17\% patients could survive 6 months without disease progression, and over $43 \%$ patients could survive 1 year or more. Given the PD-L1 expression status, we found that when PD-L1+ patients compared with global patients, similar ORR and DCR were observed (this may due to among 586 patients in this metaanalysis, 417 patients were PD-L1+), but when compared with PD-L1- patients, differences do exist. The CR was 2.52\% vs 0.00\% (PD-L1+ vs PD-L1-); the PR was $9.93 \%$ vs $2.69 \%$. Apart from that, we also observed that PD-L1+ patients even have approximately 3 times ORR and 3.6 times DCR of PD-L1- patients. Taken together, these data support the promising and durable effect of PD-1/PD-L1 inhibitors in patients who achieved a complete or partial response, and probably signal a greater benefit in the group of patients with PD-L1+ cancer types.

Based on the results from these PD-1/PD-L1 inhibitors monotherapy in patients with advanced breast cancer, conducting studies of combination therapy that might improve the treatment benefit is urgent and necessary, cause the response rate and outcome of monotherapy were not in good efficacy as we expected. Combined regimen consists of immunotherapy in combination with chemotherapy, targeted therapy, as well as radiotherapy and other agents that are able to enhance the efficacy of PD-1 or PD-L1 inhibitors.

Recently, promising clinical activity in TNBC has been reported for a combination therapy of atezolizumab administered in combination with nab-paclitaxel chemotherapy (NCT01633970) [22, 23]. Earlier studies conducted by Adams S and Tolaney S in which the treatment regimen were atezolizumab combined with taxane chemotherapy (NCT01633970) and pembrolizumab combined with eribulin mesylate (NCT02513472) respectively also showed a promising effect in TNBC patients [24]. As for combined with targeted therapy, there were immunotherapy in combination with inhibitors of CDK4/6 (cyclin-dependent kinases 4 or 6), HER2-targeted therapy, angiogenesis inhibitors, PARP inhibitors (niraparib or olaparib) and so on [25]. Apart from that, TAMs (tumor-associated macrophages) and Aurora-A inhibition also played the key role in regulating the activity of anti-PD-1/PD-L1 agents for breast cancer[26, 27]. Therefore, based on PD-1/PD-L1 inhibitors, there are various of combination regimens to be discovered and applied to clinical therapy.

When it comes to adverse events, we found that nearly 2 in 3 patients treated with anti-PD-1/PD-L1 agents experienced at least 1 adverse event, and 1 in 8 patients suffered from at least 1 grade 3 or higher adverse event. As for irAEs, nearly 1 in 6 patients experienced 1 irAEs. Due to treatment-related AEs, about 1 in 30 patients discontinued the treatment, and the rate of death was $0.30 \%$ (3 cases reported died of liver failure, DIC, multiple organ metastasis and respiratory distress). Based on these numbers, it is significant to provide relevant information to patients before they start treatment with an anti-PD-1 or PD-L1 agent.

Fatigue was the most common adverse event in all grade, about 1 in 5 patients experienced it, but nearly 1 in 100 suffered a severe grade. Although it was less likely to be severe, given its relatively high incidence, it is worth disclosing to patients. Nausea, diarrhea and hypothyroidism are the next most common allgrade adverse events (about 1 in 9 13), but the likelihood of patients experiencing severe manifestations of these adverse events is relatively low ( $\leq 1 \%$ ) except diarrhea (approximately $2 \%$ patients in severe grade). Asthenia, decreased appetite, arthraigia, pruritus and rash are the third degree most common all- 
grade adverse events (about 1 in 14 16). For those adverse events common but less likely to be severe, to inform patients is an essential part of dealing with these events.

This meta-analysis also showed that most of the most common severe grade (3 or higher adverse events) were likely immune-related, including anemia, autoimmune hepatitis, diarrhea, hepatic dysfunction and pneumonitis. According to several studies published, doctors found that pneumonitis was the most common cause of treatment-related death in patients treated with PD-1 and PD-L1 inhibitors. Apart from that, hepatitis was the adverse event found most likely to be severe if it occurred, nearly half of hepatitis being grade 3 or higher. Diarrhea was also common, and clinical vigilance is of vital necessary for early recognition and intervention to prevent serious colitis[28].

As for irAEs, manifesting as hypothyroidism (7\%) was most common, and hyperthyroidism (3\%), pneumonitis (3\%) and infusion-related reaction ( $2 \%$ ) were relatively less common. Usually these irAEs are temporary, but sometimes they can be severe or lethal. To deal with such events, it is of vital significance to monitor closely and recognize pertinent signs and symptoms early so as to provide proper management, like prompt initiation of local or systemic immunologic suppression and so on, which is of huge benefit to improve outcomes for these patients $\square$ Generally speaking, to treat moderate or severe irAEs, it is necessary to discontinue current immunotherapy and start corticosteroids treatment in time.

Detailed therapeutic scheme is based on the severity of irAEs $[29,30]$. For patients suffering moderate (grade 2) irAEs, doctors are suggested to suspend current immunotherapy, and are allowed to restart treatment when the symptoms or toxicity are alleviated $(\leq$ grade 1$)$; and if the symptoms are not alleviated within 1 week, it is necessary to initiate glucocorticoid (prednisone $0.5 \mathrm{mg} /(\mathrm{kg} \cdot \mathrm{d}$ ) or other equivalent glucocorticoid). For patients suffering severe or lifethreatening (grade 3 or 4) irAEs, doctors are suggested to suspend current immunotherapy permanently, and should start a high dosage glucocorticoid (prednisone $1-2 \mathrm{mg} /(\mathrm{kg} \cdot \mathrm{d}$ ) or other equivalent glucocorticoid) treatment as soon as possible; when the symptoms are alleviated ( $\leq$ grade 1$)$, it is allowed to gradually decrease the dosage during at least 1 month. For those who showed the symptom of immune-related diarrhea, if it is not effective during the 3-days glucocorticoid therapy, considers using infliximab $(5 \mathrm{mg} / \mathrm{kg})$; and for those patients who showed immune-related hepatitis, it is not allowed to use infliximab.

\section{Limitations}

This meta-analysis has several limitations which should be addressed. Firstly, evaluation of the sample and data set in this meta-analysis was considered to be too small for statistical or visual examination of publication bias, furthermore the probable existence of such bias could not be well determined. We assume that this meta-analysis is subject to publication bias given that all of our analyses were based on publications. Secondly, the criteria for inclusion and exclusion in each study are different, which may affect the outcome and lead to heterogeneity among studies. In addition, this study is subject to any errors or biases of the original investigators, therefore the results are generalizable only to patients eligible for these clinical trials.

\section{Conclusion}

In conclusion, this meta-analysis has revealed that durable anti-tumor clinical benefit can be achieved with anti-PD-1/PD-L1 monotherapy in a subset of patients with advanced breast cancer patients, and suggested that this treatment was generally well tolerated and had a manageable safety profile with most AEs at low grade. Survival was encouraging and promising, especially in patients with CR, PR, or SD. Besides, we also found that the presence of PD-L1 can enrich for an advanced breast cancer population with higher response rate, thus further research and elucidation of the immunologic or molecular features of responders may identify a subset of patients who have excellent outcomes with anti-PD-1/PD-L1 monotherapy. On the basis of the results from these monotherapy clinical trials, scientists have conducted many studies of combination therapy, such as immunotherapy combined with chemotherapy and so on, which might produce higher value of therapeutic efficacy for metastasis breast cancer patients. Besides, this global overview of the adverse events of anti-

PD-1/PD-L1 agents can be used as a reference by breast cancer clinicians and may guide clinical practice.

\section{Declarations}

\section{Ethics approval and consent to participate}

All procedures performed in studies involving human participants were in accordance with the ethical standards of the institutional and/or national research committee and with the 1964 Helsinki declaration and its later amendments or comparable ethical standards. Informed consent was obtained from all individual participants included in the study contained.

\section{Consent for publication}

Not applicable.

\section{Availability of data and material}

Data openly available in a public repository that issues datasets with DOls. The data that support the findings of this study are openly available in [repository name e.g "figshare"] at http://doi.org/[doi], reference number [reference number].

\section{Competing interests}

All authors including YQ, XK, XW, JZ, JW and YF declare that they have no conflict of interest. 
None of the funders of this research had any influence on the design of the study, the collection, analysis and interpretation of the data, or the writing of the manuscript.

Authors' contributions

Conceived and designed the study: YQ. Collected the literature, wrote the

manuscript: YQ, XK, XW, JZ. Revised the manuscript: JW, YF. All authors read and approved the final manuscript.

Acknowledgements

We would like to thank our colleagues at the Department of Breast Surgical Oncology, National Cancer Center/National Clinical Research Center for Cancer/Cancer Hospital, Chinese Academy of Medical and Peking Union Medical College.

\section{ABBREVIATIONS}

TNBC, triple-negative breast cancer; mTNBC, metastatic triple-negative breast cancer; MBC, metastatic breast cancer; PD-1, Programmed death-1; PD-L1, Programmed death- ligand 1; FDA, Food and Drug Administration; CR, complete response; PR, partial response; ORR, objective response rate; DCR, disease control rate; $\mathrm{AE}$, adverse events; ir-AE, immune-related AEs; CTC for AE, Common Terminology Criteria for Adverse Events; RECIST, Response Evaluation Criteria in Advanced Solid Tumors; CDK4/6, cyclin-dependent kinases 4 or 6; HER2, human epidermal growth factor receptor-2; PARP, poly ADP-ribose polymerase; TAMs, tumor-associated macrophages; DIC, disseminated intravascular coagulation.

\section{References}

1.Gennari, A., et al., Survival of metastatic breast carcinoma patients over a 20-year period. Cancer, 2005. 104(8): p. 1742-1750.

2.Chia, S. K., C. H. Speers, and D. Y. Y, The Impact of New Chemotherapeutic and Hormone Agents on Survival in a Population-based Cohort of Women with Metastatic Breast Cancer. Cancer, 2007. 19(2): p. 180-180.

3.Dafni, U., et al., Fifteen-year trends in metastatic breast cancer survival in Greece. Breast Cancer Research and Treatment, $2010.119(3)$ : p. 621-631.

4.AG, W. and W. EP, Breast Cancer Treatment: A Review. JAMA, 2019. 321(3): p. 288-300.

5.Greenberg, P. A., et al., Long-term follow-up of patients with complete remission following combination chemotherapy for metastatic breast cancer. Journal of Clinical Oncology, 1996. 14(8): p. 2197-2205.

6.Kiely, B. E., et al., How Long Have I Got? Estimating Typical, Best-Case, and Worst-Case Scenarios for Patients Starting First-Line Chemotherapy for Metastatic Breast Cancer: A Systematic Review of Recent Randomized Trials. Journal of Clinical Oncology, 2011. 29(4): p. 456-463.

7.Beslija, S., et al., Consensus on Medical Treatment of Metastatic Breast Cancer. Breast Cancer Research and Treatment, 2003. 81(S1): p. 1-7.

8.Pagani, O., et al., International Guidelines for Management of Metastatic Breast Cancer: Can Metastatic Breast Cancer Be Cured? JNCl Journal of the National Cancer Institute, 2010. 102(7): p. 456-463.

9.Wahba, H. A. and H. A. El-Hadaad, Current approaches in treatment of triple-negative breast cancer. Cancer biology \& medicine, 2015. $12(2):$ p. 106-16.

10.den Brok, W. D., et al., Survival with metastatic breast cancer based on initial presentation, de novo versus relapsed. Breast Cancer Research and Treatment, 2017. 161(3): p. 549-556.

11.Dent, R., et al., Triple-Negative Breast Cancer: Clinical Features and Patterns of Recurrence. Clinical Cancer Research, 2007. 13(15): p. 4429-4434.

12.Anders, C. K., et al., The Evolution of Triple-Negative Breast Cancer: From Biology to Novel Therapeutics. American Society of Clinical Oncology Educational Book, 2016. 36: p. 34-42.

13.Wang, X., et al., Immunological therapy: A novel thriving area for triple-negative breast cancer treatment. Cancer Letters, 2019. 442: p. 409-428.

14.Higgins, J. P. T., et al., The Cochrane Collaboration's tool for assessing risk of bias in randomised trials. BMJ. p. 889-893.

15.Nanda, R., et al., Pembrolizumab in Patients With Advanced Triple-Negative Breast Cancer: Phase lb KEYNOTE-012 Study. Journal of Clinical Oncology, 2016. 34(21): p. 2460-2467.

16.Dirix, L. Y., et al., Avelumab, an anti-PD-L1 antibody, in patients with locally advanced or metastatic breast cancer: a phase 1b JAVELIN Solid Tumor study. Breast Cancer Research and Treatment, 2018. 167(3): p. 671-686.

17.Rugo, H. S., et al., Safety and Antitumor Activity of Pembrolizumab in Patients with Estrogen Receptor-Positive/Human Epidermal Growth Factor Receptor 2-Negative Advanced Breast Cancer. Clinical Cancer Research, 2018. 24(12): p. 2804-2811. 
18.S, A., et al., Pembrolizumab monotherapy for previously treated metastatic triple-negative breast cancer: cohort A of the phase II KEYNOTE-086 study. Annals of oncology: official journal of the European Society for Medical Oncology, 2019. 30(3): p. 397-404.

19.Adams, S., et al., Pembrolizumab monotherapy for previously treated metastatic triple-negative breast cancer: cohort A of the phase II KEYNOTE-086 study. Annals of Oncology, 2019. 30(3): p. 397-404.

20.Emens, L. A., et al., Long-term Clinical Outcomes and Biomarker Analyses of Atezolizumab Therapy for Patients With Metastatic Triple-Negative Breast Cancer. JAMA Oncology, 2019. 5(1): p. 74-74.

21.AC, S. Breast cancer survival rates. https://www.cancer.org 2017 [cited 201828 March].

22.Atezolizumab and Nab-Paclitaxel in Advanced Triple-Negative Breast Cancer. New England Journal of Medicine, 2019. 380(10): p. 985-988.

23.Cyprian, F. S., et al., Targeted immunotherapy with a checkpoint inhibitor in combination with chemotherapy: A new clinical paradigm in the treatment of triple-negative breast cancer. Bosnian Journal of Basic Medical Sciences, 2019.

24.Tolaney, S., et al., Phase 1b/2 study to evaluate eribulin mesylate in combination with pembrolizumab in patients with metastatic triple-negative breast cancer. European Journal of Cancer, 2017. 72: p. S16-S16.

25.Esteva, F. J., et al., Immunotherapy and targeted therapy combinations in metastatic breast cancer. The Lancet. Oncology, 2019. 20(3): p. e175-e186.

26.Santoni, M., et al., Triple negative breast cancer: Key role of Tumor-Associated Macrophages in regulating the activity of anti-PD-1/PD-L1 agents.

Biochimica et Biophysica Acta (BBA) - Reviews on Cancer, 2018. 1869(1): p. 78-84.

27.Yin, T., et al., Aurora-A inhibition eliminates myeloid cell-mediated immunosuppression and enhances the efficacy of anti-PD-L1 therapy in breast cancer. Cancer Research, 2019: p. canres.3397.2018-canres.3397.2018.

28.Wang, Y., et al., 1160PMeta-Analysis of Anti-PD-1/PD-L1 Therapy Related Adverse Events in Clinical Trials. Annals of Oncology, 2017. 28(suppl_5).

29.Puzanov, l., et al., Managing toxicities associated with immune checkpoint inhibitors: consensus recommendations from the Society for Immunotherapy of Cancer (SITC) Toxicity Management Working Group. Journal for ImmunoTherapy of Cancer, 2017. 5(1): p. 95-95.

30.Brahmer, J. R., C. Lacchetti, and J. A. Thompson, Management of Immune-Related Adverse Events in Patients Treated With Immune Checkpoint Inhibitor Therapy: American Society of Clinical Oncology Clinical Practice Guideline Summary. Journal of Oncology Practice, 2018. 14(4): p. 247-249.

\section{Tables}




\begin{tabular}{|c|c|c|c|c|c|c|c|c|c|c|c|c|c|c|}
\hline \multirow[t]{2}{*}{ NCT Number } & \multirow[t]{2}{*}{ Title } & \multirow[t]{2}{*}{ Status } & \multirow[t]{2}{*}{ Conditions } & \multirow[t]{2}{*}{ Interventions } & \multicolumn{4}{|c|}{ Characteristics } & \multicolumn{3}{|c|}{ Population } & \multirow{2}{*}{$\begin{array}{l}\text { Follow- } \\
\text { up } \\
\text { Time } \\
\text { Frame }\end{array}$} & \multirow{2}{*}{$\begin{array}{r}\text { CTC } \\
\text { for AF } \\
\text { versio }\end{array}$} & \multirow{2}{*}{$\begin{array}{l}\text { REC } \\
\text { E vers } \\
\text { n }\end{array}$} \\
\hline & & & & & Study Type & Phase & $\begin{array}{l}\text { Study } \\
\text { Design }\end{array}$ & $\begin{array}{c}\text { Outcome } \\
\text { Measures }\end{array}$ & Enrollment & Age & & & & \\
\hline Emens, 2018 NCT01375842 & $\begin{array}{c}\text { A Study of } \\
\text { Atezolizumab (an } \\
\text { Engineered Anti- } \\
\text { Programmed } \\
\text { Death-Ligand } 1 \\
\text { [PDL1] Antibody) } \\
\text { to Evaluate } \\
\text { Safety, } \\
\text { Tolerability and } \\
\text { Pharmacokinetics } \\
\text { in Participants } \\
\text { With Locally } \\
\text { Advanced or } \\
\text { Metastatic Solid } \\
\text { Tumors }\end{array}$ & 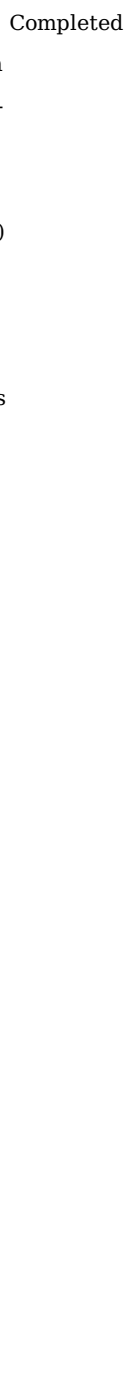 & $\begin{array}{c}\text { •Breast } \\
\text { Cancer } \\
\text { (advanced } \\
\text { TNBC) } \\
\text { •Tumors } \\
\text { •Hematologic } \\
\text { Malignancies }\end{array}$ & $\begin{array}{l}\text { •Biological: } \\
\text { Atezolizumab } \\
(15 \text { or } 20 \\
\mathrm{mg} / \mathrm{kg} \text {, or at a } \\
1200 \text {-mg flat } \\
\text { dose, every } 3 \\
{ }_{\text {s }}^{\text {weeks })}\end{array}$ & Interventional & $\begin{array}{r}\text { Phase } \cdot A \\
1 \quad \mathrm{R}\end{array}$ & $\begin{array}{l}\text { Intervention } \\
\text { Model: } \\
\text { Parallel } \\
\text { Assignment } \\
\text { ·Masking: } \\
\text { None (Open } \\
\text { Label) } \\
\text { ·Primary } \\
\text { Purpose: } \\
\text { Treatment }\end{array}$ & 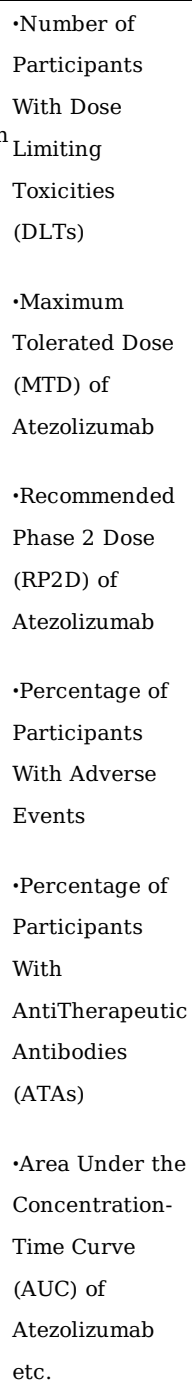 & $\begin{array}{c}(115 \\
\text { breast } \\
\text { cancer } \\
\text { patients) }\end{array}$ & $\begin{array}{c}18 \\
\text { Years } \\
\text { and } \\
\text { older } \\
\text { (Adult, } \\
\text { Older } \\
\text { Adult) }\end{array}$ & All & $\begin{array}{c}\text { Up to } \\
84 \\
\text { months }\end{array}$ & 4 & 1. \\
\hline
\end{tabular}




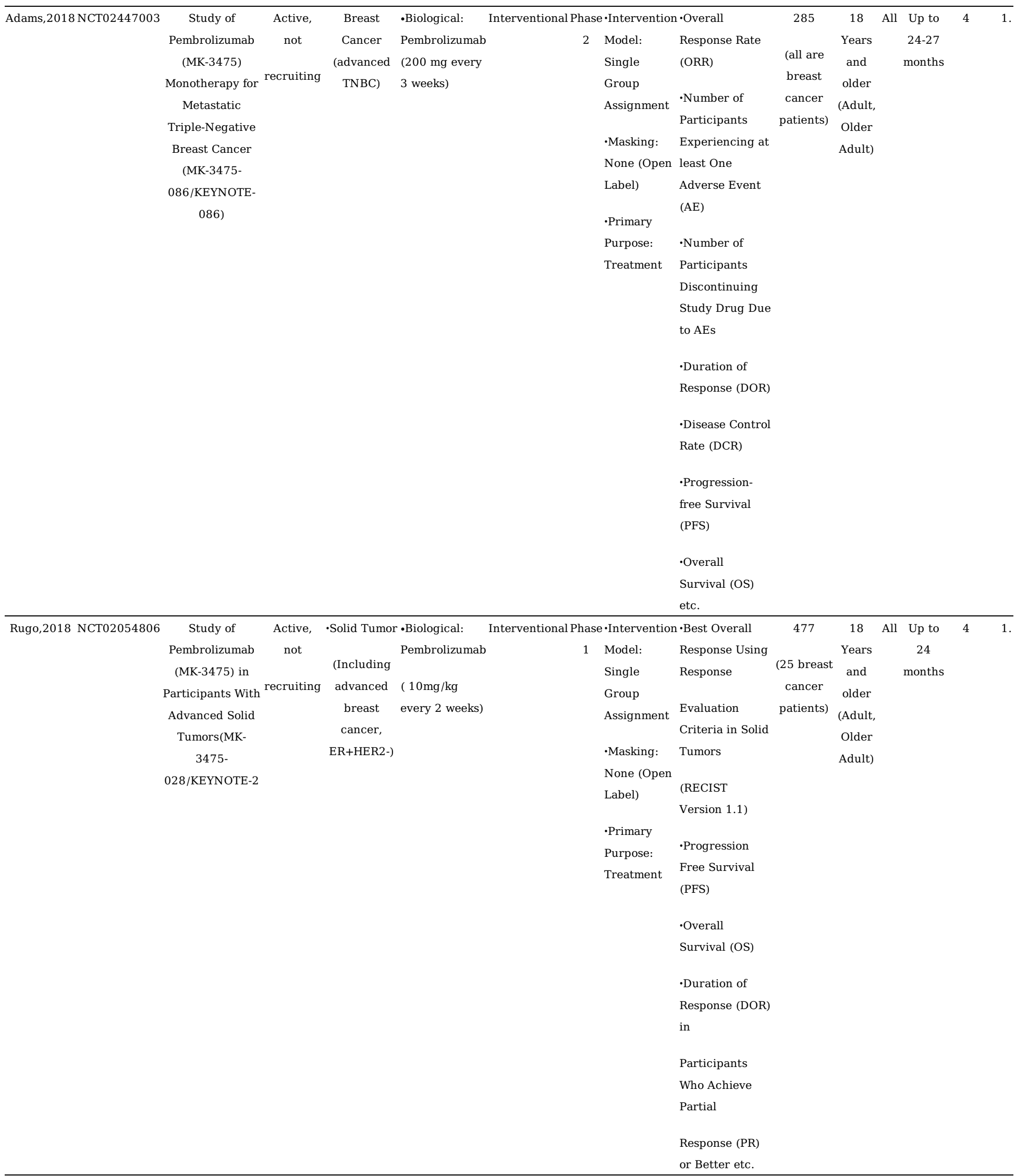




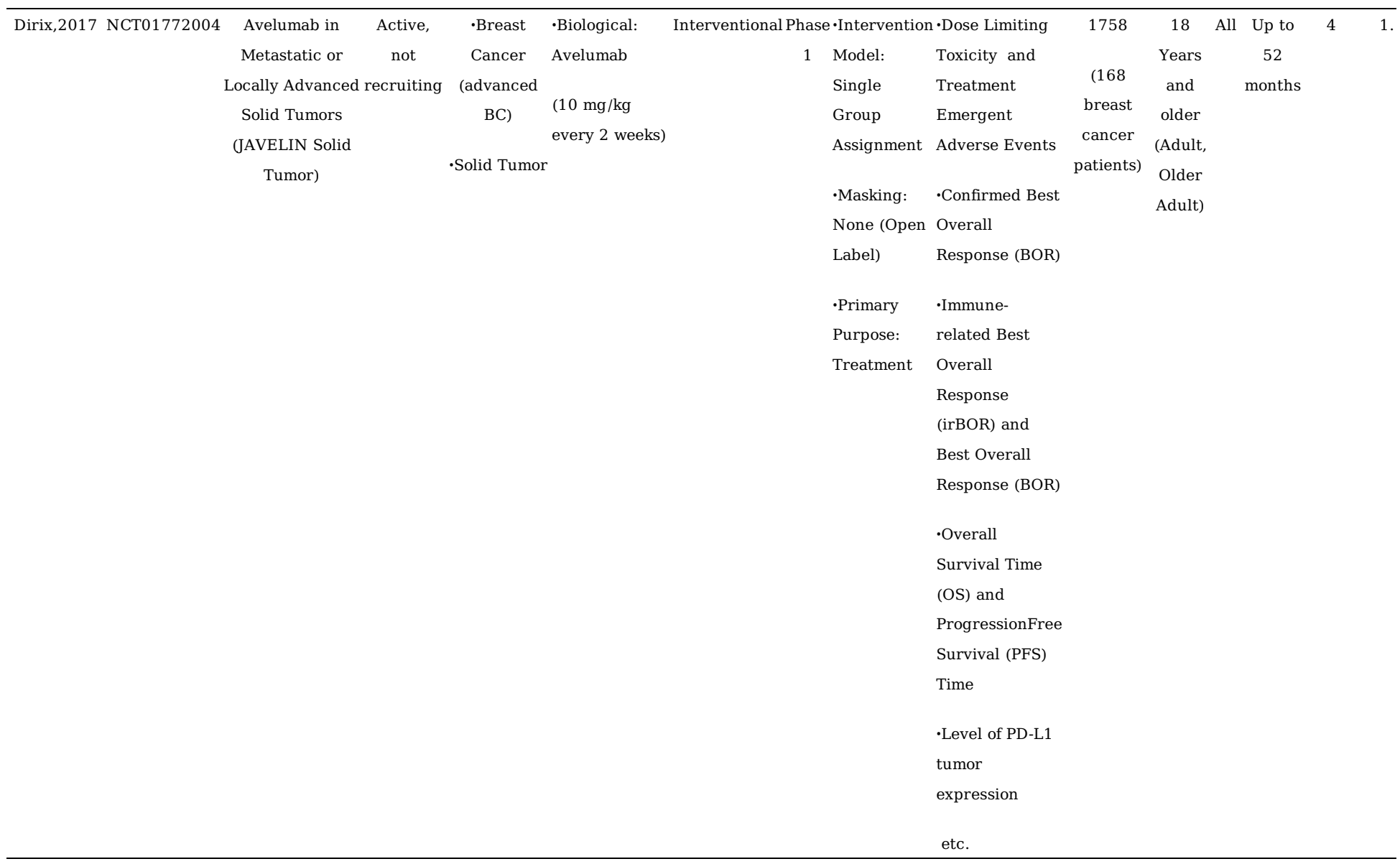




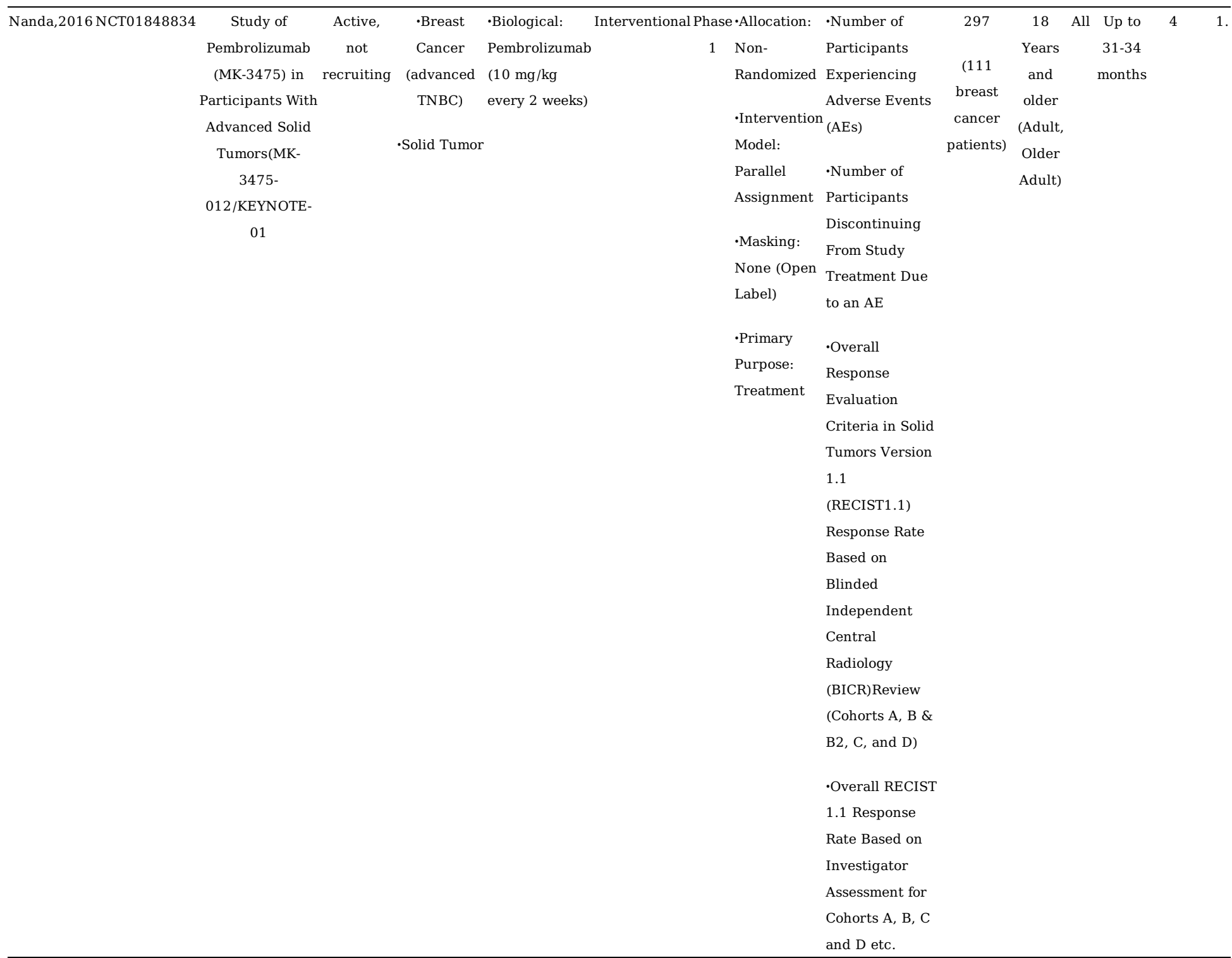

CTC for AE version, Common Terminology Criteria for Adverse Events version

RECIST version, Response Evaluation Criteria in Advanced Solid Tumors version

$T N B C$, Triple Negative Breast Cancer; ER+,Estrogen receptor-positive;

HER2-, Human Epidermal Growth Factor Receptor 2-negative 


\begin{tabular}{|c|c|c|c|c|c|c|c|c|}
\hline Study & Year & Randomization & Allocation concealment & Blinding of participants and staff* & * Blinding of outcome assessors & Incomplete outcome data & Selective outcome reporting & Other sources of bias \\
\hline AdamsA & 2018 & & Low & Low & Low & Low & Low & Low \\
\hline AdamsB & 2018 & Low & Low & Low & Low & Low & Low & Low \\
\hline Emens & 2018 & & Low & Low & Low & Low & Low & Low \\
\hline Rugo & $2018 \mid$ & Low & Low & Low & Low & Low & Low & Low \\
\hline Dirix & 2017 & Low & Low & Low & Low & Low & Low & Low \\
\hline Nanda & 2016 & & Low & Low & Low & Low & Low & Low \\
\hline Kappa & NA & 1.00 & 1.00 & 1.00 & 0.629 & 1.00 & 1.00 & 1.00 \\
\hline \multicolumn{9}{|c|}{$\mathrm{NA}=$ not applicable. } \\
\hline
\end{tabular}

\section{Figures}

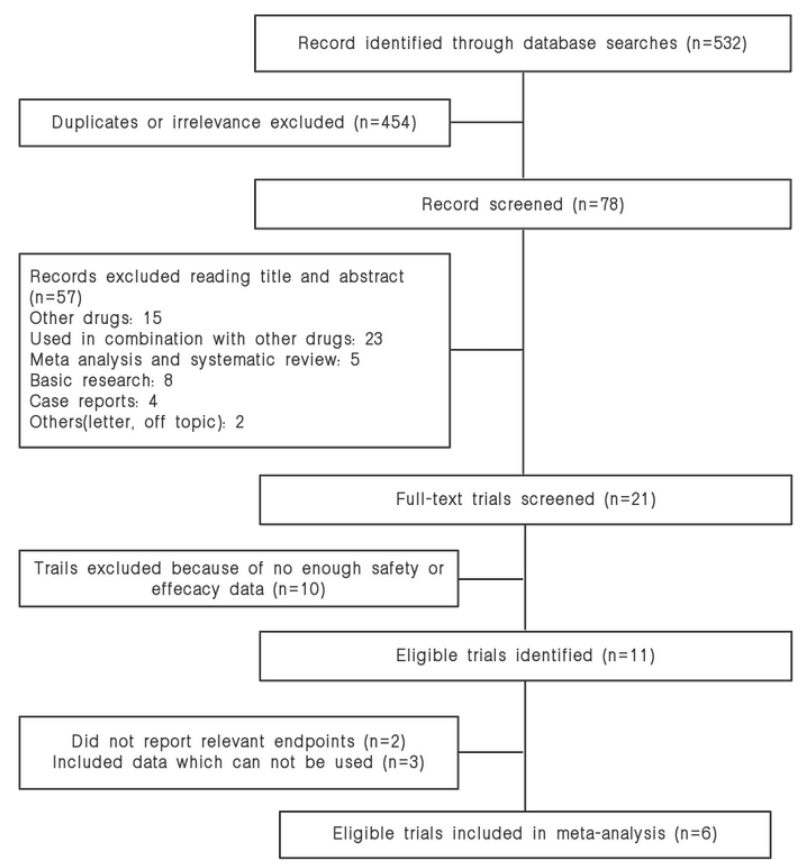

Figure 1

Flow diagram for identification and selection of studies included in the meta-analysis

Page 12/21 

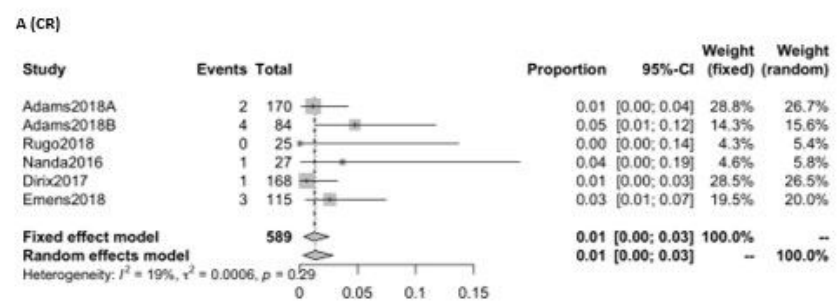

B (PR)

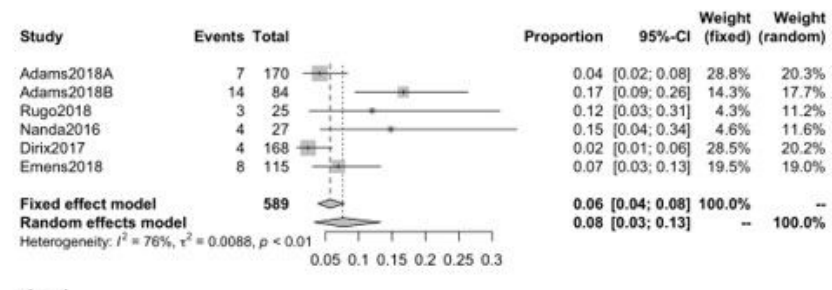

C (ORR)

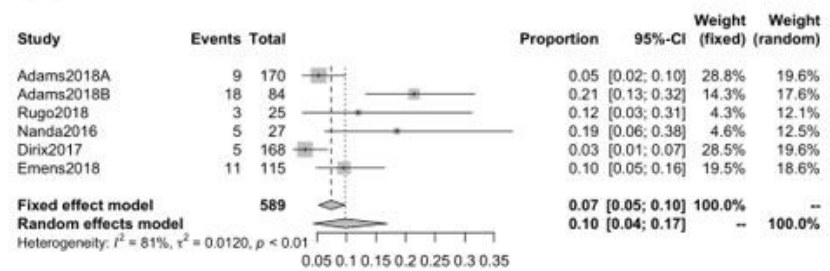

$D$ (DCR)

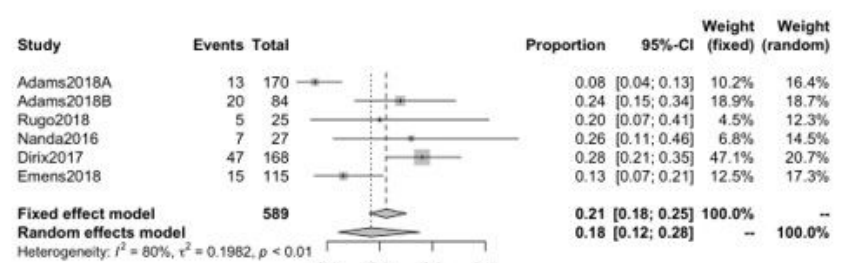

\section{Figure 2}

The global response rate for patients of CR (A), PR (B), ORR (C) and DCR (D) 
A (1-year OS rate)

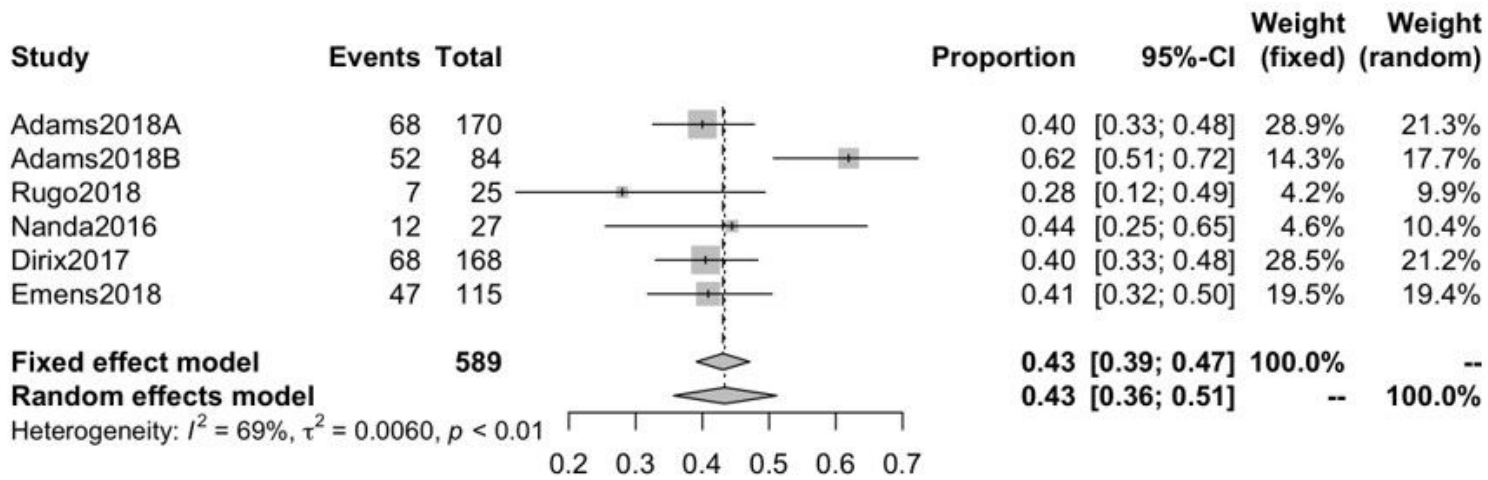

\section{B (6-months PFS rate)}

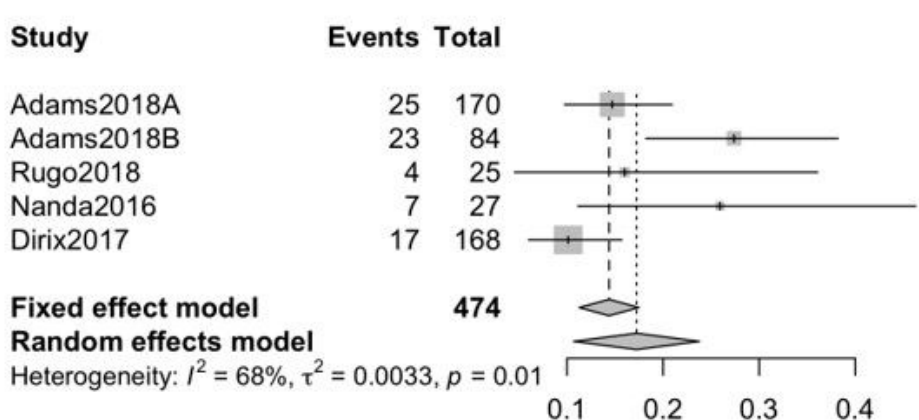

$\begin{array}{rrrr}\text { Proportion } \quad \mathbf{9 5 \% - C l} & \begin{array}{r}\text { Weight } \\ \text { (fixed) }\end{array} & \begin{array}{r}\text { Weight } \\ \text { (random) }\end{array} \\ & & & \\ 0.15[0.10 ; 0.21] & 34.3 \% & 27.7 \% \\ 0.27[0.18 ; 0.38] & 10.7 \% & 19.7 \% \\ 0.16[0.05 ; 0.36] & 4.7 \% & 12.9 \% \\ 0.26[0.11 ; 0.46] & 3.6 \% & 10.7 \% \\ 0.10[0.06 ; 0.16] & 46.7 \% & 29.1 \% \\ & & \\ \mathbf{0 . 1 4}[\mathbf{0 . 1 1} ; \mathbf{0 . 1 7}] & \mathbf{1 0 0 . 0 \%} & - \\ \mathbf{0 . 1 7}[\mathbf{0 . 1 1} ; \mathbf{0 . 2 4}] & - & \mathbf{1 0 0 . 0 \%}\end{array}$

Figure 3

1-year OS rate (A) and 6-months PFS rate (B) 
A (CR)

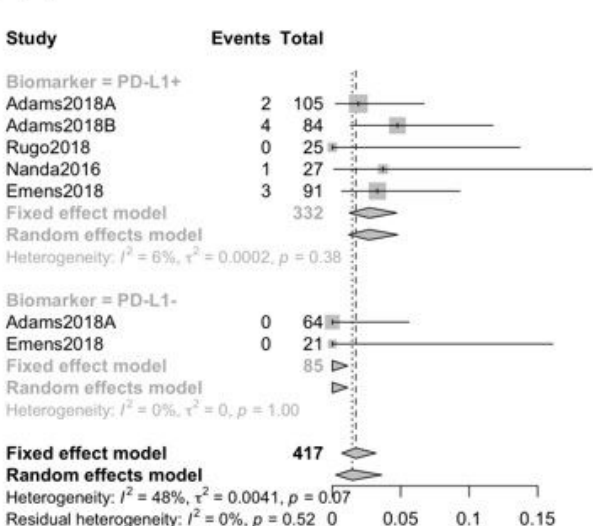

Proportion $\quad 95 \%-\mathrm{Cl} \quad \begin{aligned} & \text { Weight } \\ & \text { (fixed) (random) }\end{aligned}$

$0.02[0.00 ; 0.07] \quad 25.2 \% \quad 19.9 \%$ $0.05[0.01 ; 0.12] \quad 20.1 \% \quad 18.2 \%$ $0.00[0.00 ; 0.14] \quad 6.0 \%-9.2 \%$ $0.04[0.00 ; 0.19] \quad 6.5 \% \quad 9.7 \%$ $0.03[0.01 ; 0.09] \quad 21.8 \% \quad 18.8 \%$ $\begin{aligned} & 0.03[0.01 ; 0.05] \\ & 0.03[0.01: 0.05]\end{aligned} 79.6 \% \quad-\quad 75.8 \%$

0.00 $0.00[0.00 ; 0.06] \quad 15.3 \% \quad 16.1 \%$ $0.00[0.00 ; 0.16] \quad 5.0 \% \quad 8.1 \%$ $0.00[0.00 ; 0.01] \quad 20.4 \%$

$0.02[0.01 ; 0.03] 100.0 \%$ $0.01[0.00 ; 0.04] \quad-\quad 100.0 \%$

B (PR)

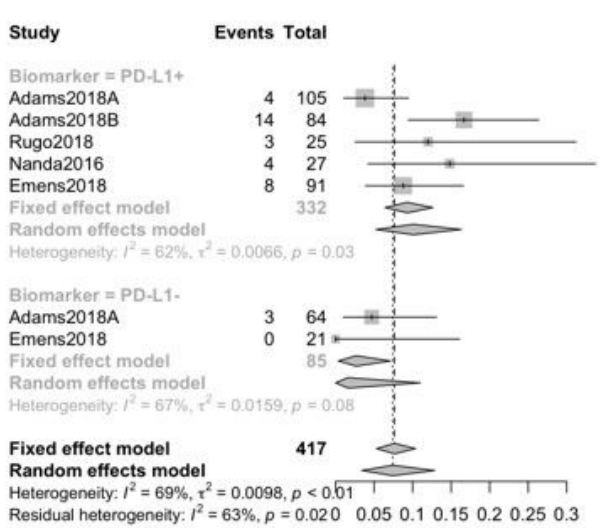

Proportion $\quad 95 \%-\mathrm{Cl}$ Weight $\begin{gathered}\text { Weight } \\ \text { (fixed) (random) }\end{gathered}$

$0.04[0.01 ; 0.09] \quad 25.2 \% \quad 17.8 \%$ $0.17[0.09 ; 0.26] \quad 20.1 \% \quad 16.9 \%$ $0.12[0.03 ; 0.31] \quad 6.0 \% \quad 10.9 \%$ $0.15[0.04 ; 0.34] \quad 6.5 \% \quad 11.3 \%$ $0.09[0.04 ; 0.17] \quad 21.8 \% \quad 17.3 \%$ $0.10[0.05 ; 0.16] \quad-\quad 74.2 \%$

$0.05[0.01 ; 0.13] \quad 15.3 \% \quad 15.8 \%$ $0.00[0.00 ; 0.16] \quad 5.0 \% \quad 10.0 \%$ $0.03[0.00 ; 0.07] 20.4 \%$

$0.02[0.00 ; 0.11] \quad-\quad 25.8 \%$

$0.08[0.05 ; 0.10] 100.0 \%$ $0.07[0.03 ; 0.13] \stackrel{-}{-} 100.0 \%$

\section{Figure 4}

The global response rate between PD-1+ and PD-L1- for patients of CR (A), PR (B) 


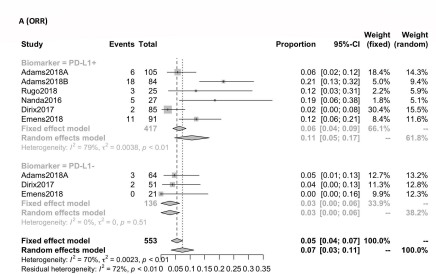

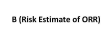

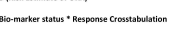
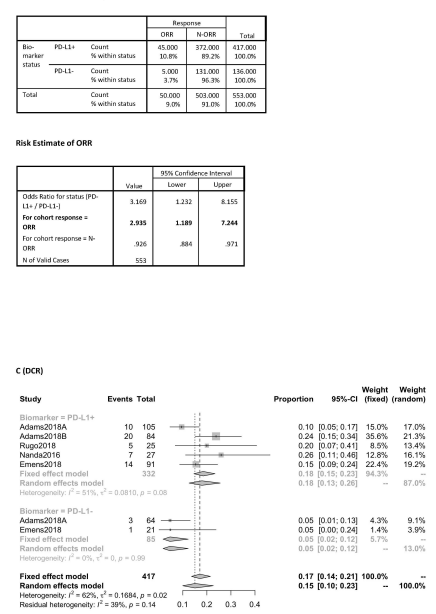

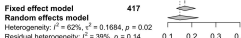

$0.211100 .9 \%$

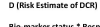

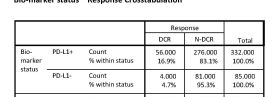

\section{Figure 5}

The global response rate and risk estimate between PD-1+ and PD-L1- for patients of ORR (A) and DCR (B) 
A (Incidence of AEs in any grade)

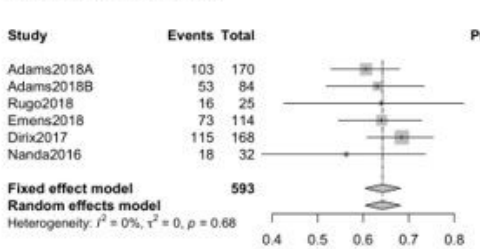

Proportion 95\%-Cl Weight Woight

$\begin{array}{llll}0.61 & {[0.53 ; 0.68]} & 24.7 \% & 24.7 \%\end{array}$

$\begin{array}{llll}0.63 & {[0.52,0.73]} & 13.6 \% & 13.6 \% \\ 0.64 & {[0.43 ; 0.82]} & 4.2 \% & 4.2 \%\end{array}$

$\begin{array}{llll}0.64 & {[0.55 ; 0.73]} & 19.2 \% & 19.2 \% \\ 0.68 & {[0.61 ; 0.75]} & 34.5 \% & 34.5 \%\end{array}$

$\begin{array}{llll}0.68 & {[0.61 ; 0.75]} & 34.5 \% & 34.5 \% \\ 0.56 & {[0.38 ; 0.74]} & 3.9 \% & 3.9 \%\end{array}$

$0.64[0.60 ; 0.68] 100.0 \% \%$ - $0.60 \%$

B (Incidence of AEs in severe grade)

Study

Events Total

$\begin{array}{cc}22 & 170 \\ 8 & 84\end{array}$

$\begin{array}{rr}22 & 170 \\ 8 & 84 \\ 4 & 25 \\ 5 & 15\end{array}$

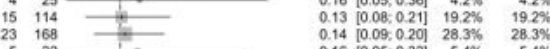

$0.16[0.05 ; 0.33] \quad 5.4 \% \quad 5.4 \%$

$0.13[0.10 ; 0.16] 100.0 \%$
$0.13[0.10 ; 0.16]$

Fixed effect model

593

$\sum_{1,1,1,1}$

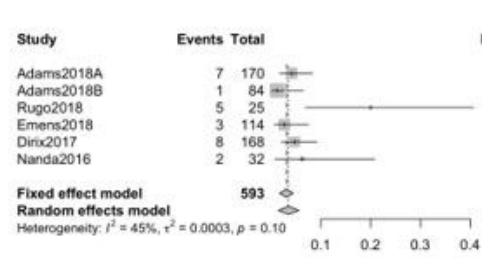

Proportion $95 \%-\mathrm{Cl}$ Weight Weight

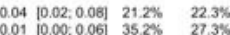
$\begin{array}{rrrr}0.01 & 10.00 ; 0.06] & 35.2 \% & 27.3 \% \\ 0.20 & 10.07 ; 0.41] & 0.8 \% & 1.7 \%\end{array}$

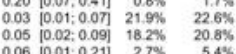
$0.06[0.01 ; 0.21] \quad 2.7 \% \quad 5.4 \%$ $0.03[0.02 ; 0.04] 100.0 \%$ - $0.00 . \overline{0}$

$E$ (Incidence of death)

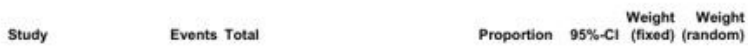

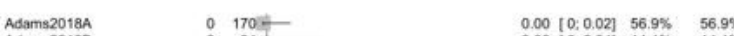
Adams2018

Emens2018

Dirix2017

Nanda2016

Fixed effect model

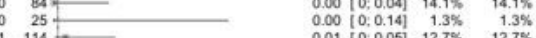

$0.01[0 ; 0.05] \quad 12.7 \% \quad 12.7 \%$

$\begin{array}{rrr}0.03[0 ; 0.16] & 1.0 \% & 1.0 \%\end{array}$

$0.00[0 ; 0.01]-100.0 \%$

593

C(Incidence of iraEs)

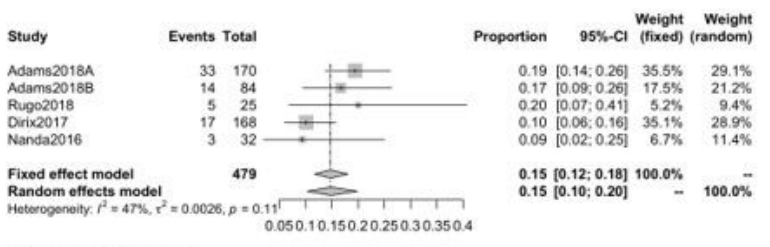

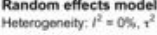
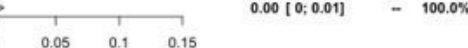

\section{Figure 6}

Global Incidence of AEs in any grade (A), in severe grade (B), irAEs (C), discontinue (D) and death (E). 


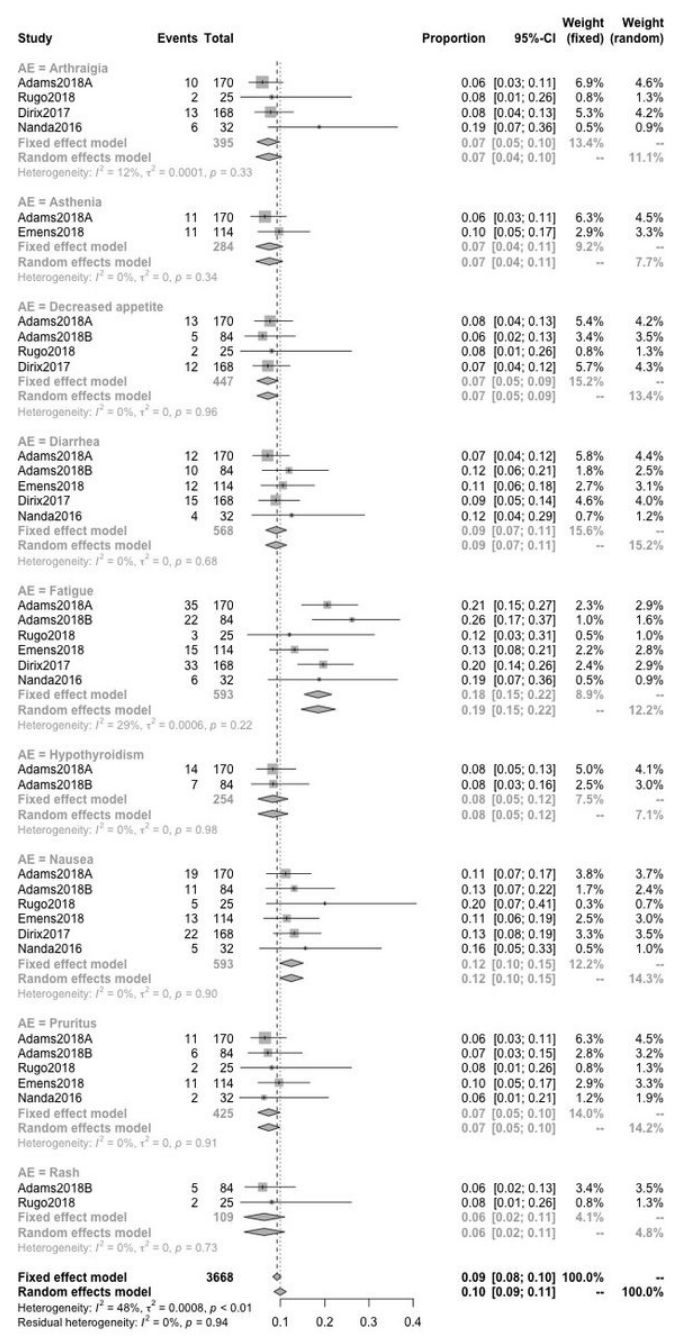

Figure 7

The detailed incidence of treatment-related AEs in any grade 


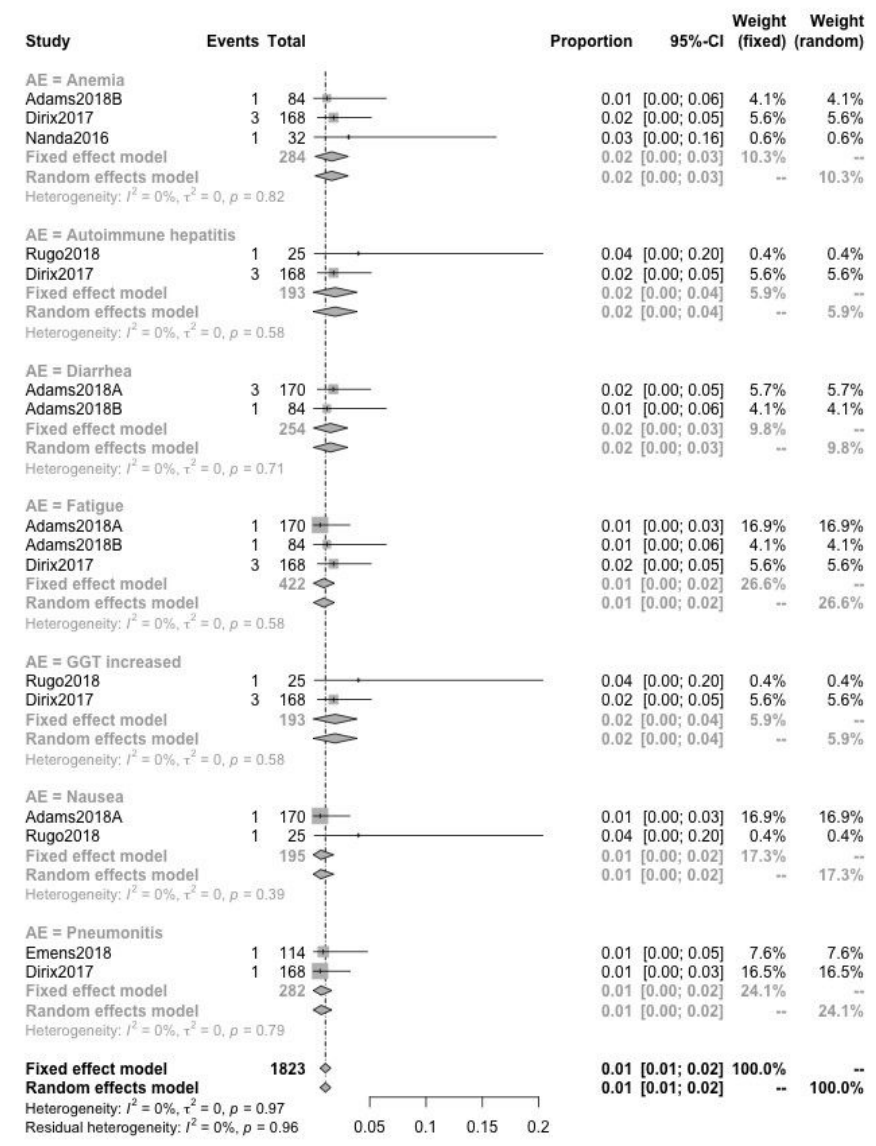

\section{Figure 8}

The detailed incidence of treatment-related AEs in severe grade. 


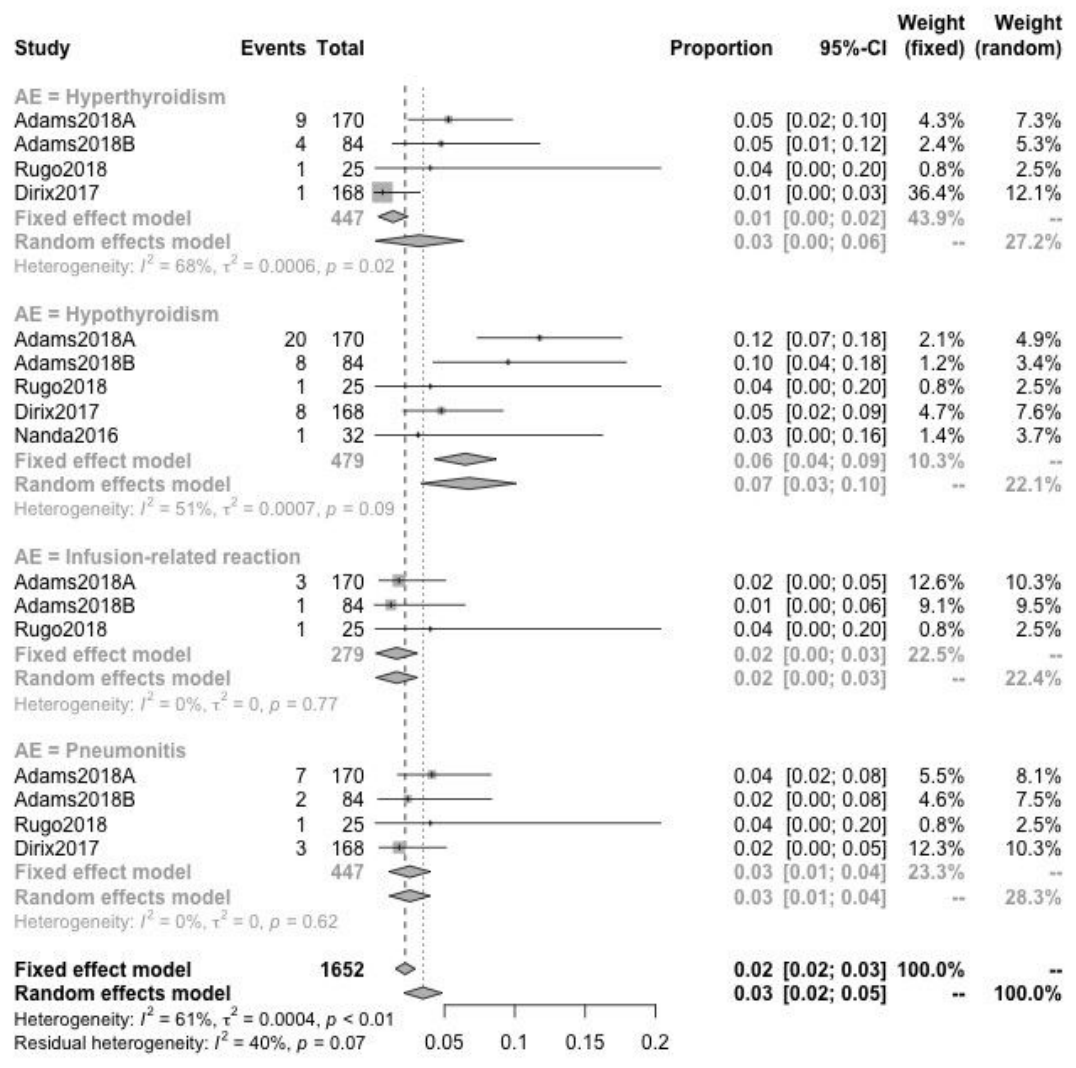

\section{Figure 9}

The detailed incidence of immune-related AEs in any grade 


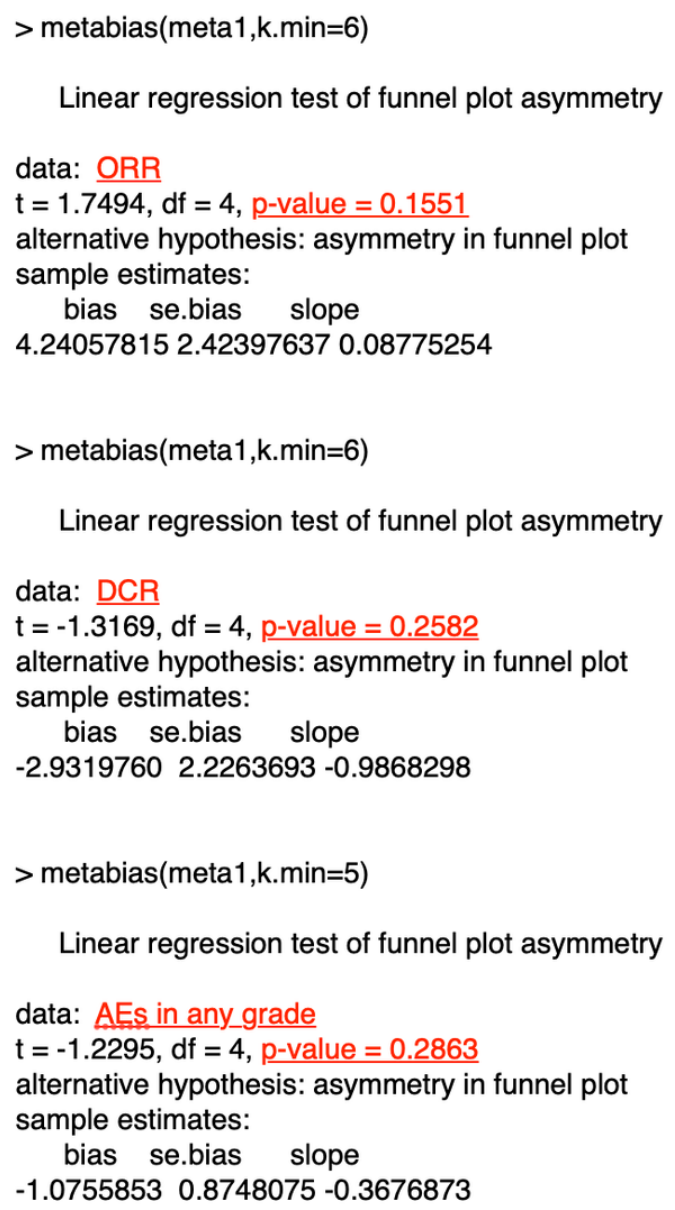

\section{Figure 10}

The Egger's test of ORR, DCR and AEs in any grade 